\title{
Photovoltaic Cells Energy Performance Enhancement with Down- Converting Photoluminescence Phosphors
}

\author{
Abdulla Tahhan ${ }^{1, *},{ }^{\dagger}$, Zahir Dehouche ${ }^{1}$, George R. Fern ${ }^{2}$ and Erik Haverkamp ${ }^{3}$ \\ ${ }^{1}$ College of Engineering, Design and Physical Sciences, Brunel University London, Uxbridge, UB8 3PH, UK. \\ ${ }^{2}$ Centre for Phosphors and Display Materials, Brunel University London, Uxbridge, UB8 3PH, UK. \\ ${ }^{3}$ ReRa Solutions BV, Bijsterhuizen 1158c, 6546 AS Nijmegen, The Netherlands.
}

\section{SUMMARY}

Phosphors, synthesized by the urea homo-precipitation method, were examined as UV-spectral down conversion materials for improving the light absorption and electrical characteristics of commercial single-junction silicon solar cells. The PV cells were coated with Erbium and Terbium doped Gadolinium Oxysulfide phosphors encapsulated in EVA binder using blade screen printing technique, and the optimum concentration of phosphor in the composite resulted in the largest light conversion, and superior electrical output and energy transfer efficiency. Moreover, the results demonstrated that the composition of dispersed phosphors has a strong influence on the amount of UV-light converted and electron transition capacity of PV cells. The experimental results showed in an optimized PV cell, an enhancement of $0.54 \%$ (from $12.11 \%$ to $12.65 \%$ ) in the energy conversion of a Si-based PV cell was achieved.

\section{Key words}

Down conversion, Ethylene Vinyl-Acetate, Monocrystalline silicon, Photovoltaic, Rare earths, Solar cells.

\section{Correspondence}

*Abdulla Tahhan, College of Engineering, Design and Physical Sciences, Brunel University London, Uxbridge, UB8 3PH, UK.

$\dagger$ †-mail: Abdulla.tahhan@brunel.ac.uk

\section{INTRODUCTION}

Currently, PV modules that dominate the market are based on crystalline silicon because of its abundance, stability and non-toxicity [1]. These PV devices suffer from different losses caused by reflection, recombination, resistive and thermal losses. The thermalisation of charge carriers is the most common loss caused by absorption of photons having energy greater than the band gap of the material of the solar cell. These losses limit the theoretical efficiency of conventional single junction solar cell to $31 \%$ [2]. Exceeding theoretical efficiency of conventional single junction solar cell could be achieved by preventing the thermalisation of charge carriers with the help of Down Conversion (DC) materials in nanoscale. Nanomaterials of various sizes and chemical compositions have demonstrated capabilities in enhancing photons conversion efficiency of solar cells at all wavelengths [3]. Using DC materials in PV can enhance the efficiency of the solar cells by using the process of absorbing high energy photons and remitting them at longer wavelengths where the solar cells show significantly better responses. Using this technique, a better harvest of the solar spectrum is obtained through expanding the operating range toward the ultraviolet (UV) band. The potential of using an ideal DC material to improve the efficiency of a silicon solar cell under un-concentrated sunlight has been demonstrated theoretically and reaches an efficiency of $38.6 \%$ [4]. The 
thermodynamic evaluation of the DC materials shows a 7\% possible enhancement in the efficiency of single junction solar cell without the presence of light concentration [5].

The DC mechanism works by elevating the current of the solar cell by increasing the number of photons absorbed while maintaining the voltage, since the DC modify only the solar spectrum to better match the solar cell light-absorption properties and not the solar cell intrinsic structure. Therefore, an increase in current would result in an increase in the conversion efficiency of the solar cell.

The potential of DC materials to improve the conversion efficiency of the single junction crystalline solar cells using spectral conversion technique by employing down conversion phosphors has attracted many researchers. DC materials can be incorporated in different methods in the PV modules such as incorporating phosphors in a commercial encapsulation binder [6], doping the top float glass of module [7] or by depositing the phosphor directly on top of the silicon solar cell [8]. Researchers demonstrated an enhancement in the performance of the solar cells by applying luminescent encapsulation binder using different techniques. Wang et al. achieved $0.42 \%$ absolute enhancement in the conversion efficiency of multi-crystalline silicon cell by soaking pre-existed EVA sheets in luminescent solution of $\mathrm{Eu}^{+3}$ complexes [9].

Yen-Chi et al. has demonstrated an absolute increase of $0.64 \%$ in the power conversion efficiency of multi-crystalline silicon solar cell by screen printing a $\mathrm{KCaGd}\left(\mathrm{PO}_{4}\right)_{2}: \mathrm{Eu}^{3+}$ phosphor dispersed in PMMA matrix [10]. Chung el al. showed an increased in power conversion efficiency of a crystalline solar cell by up to a factor of 14 under UV illumination using $\mathrm{Y}_{2} \mathrm{O}_{2} \mathrm{~S}: \mathrm{Eu}^{+3}$ dispersed in PMMA polymerand applied on the cell using spin coating technique [6]. Also, this technique was used by Marchionna et al. who demonstrated $1 \%$ absolute enhancement of the delivered power of commercial mono-crystalline solar cell for the case of Air Mass 0 lightning conditions with an active coating of poly-vinyl acetate film doped with Phenanthroline-Eu ${ }^{3+}$ complex [11].

A pyramidally textured structure of $\mathrm{Si}_{3} \mathrm{~N}_{4}$ coated on the surface of the c-Si solar cell is widely used to increase the absorbance of the solar light [13]. The emission of the phosphor is unidirectional and the emitted light can be emitted in all direction. Subsequently, when the DC material is placed on top of silicon solar cell, it is only expected that half of the luminescence emitted by down converter contributes to photocurrent emitted into the direction of the solar cell [4]. However, the pyramidally textured surface can reduce this loss and thus more exploited photons can contribute in generation of charge carries and consequently increasing the conversion efficiency.

We selected $\mathrm{Gd}_{2} \mathrm{O}_{2} \mathrm{~S}\left(\mathrm{Er}_{0.2}, \mathrm{~Tb}\right)_{0.01}$ phosphor with a lower refractive index than $\mathrm{Si}$ or $\mathrm{Si}_{3} \mathrm{~N}_{4}$ that may be capable of converting more UV photons into longer wavelength where Si based solar cell shows a greater response. In this study, we examine the potential of the application of down conversion $\mathrm{Gd}_{2} \mathrm{O}_{2} \mathrm{~S}\left(\mathrm{Er}_{0.2}, \mathrm{~Tb}\right)_{0.01}$ phosphor to improve the efficiency of PV solar cell as well as demonstrate the use of low cost implementation method to form a luminescent layer on top of commercial monocrystalline photovoltaic cell by using doctor blade screen printing technique [14]. In addition to the investigation of the microstructure of the down converting layer using Scanning Electron Microscopy $(\mathrm{SEM})$, open circuit voltage $\left(\mathrm{V}_{\mathrm{OC}}\right)$, short circuit current $\left(\mathrm{I}_{\mathrm{SC}}\right)$ and power conversion efficiency $(\eta)$ of the coated cells were measured and compared to uncoated cells. The reflectance, transmission and photoluminescence analyses of the down converting layer are also presented.

\section{EXPERIMENTAL}

1) Layer Preparation:

Phosphor nano-powder $\mathrm{Gd}_{2} \mathrm{O}_{2} \mathrm{~S}\left(\mathrm{Er}_{0.2}, \mathrm{~Tb}\right)_{0.01}$ produced at Centre for Phosphors and Display Materials [12] was used in the experiments. Different mass weights of the phosphor powder of $(1,3,5,7) \mathrm{mg}$ were dispersed in P-Xylene using ultrasonic bath then the photoluminescent solution is well mixed with EVA in ratios of $18 \mathrm{wt} \%$. Different concentrations of the phosphor powder were used in an 
attempt to find the best concentration of the phosphor powder to the EVA that result in an optimum energy conversion enhancement in the PV cell.

2) Layer Application:

Mono-Crystalline Silicon solar cells XS156B3 from Motech were used. The c-Si solar cells with an area of $15.6 \times 15.6 \mathrm{~cm}^{2}$ were cut into three equal sizes by CTR TMX90 laser machine. The Phosphor/EVA mixture is then blade screen printed on top of random pyramids structure of $\mathrm{Si}_{3} \mathrm{~N}_{4}$ reflective layer of the solar cells. Only an area of $3 \times 3 \mathrm{~cm}^{2}$ of each cell was coated. Then, the coated cells were heated in the furnace to $190^{\circ} \mathrm{C}$ at a rate of $10^{\circ} \mathrm{C} / \mathrm{min}$. After the heating step, leads were welded on them. The applied mixture of Phosphor and EVA formed a layer with a thickness of about $9 \mu \mathrm{m}$ on the surface of the solar cell. A schematic of the luminescent layer applied on top of solar cell is illustrated in Figure 1.

3) EVA layer:

Ethyl Vinyl-Acetate (EVA) was used in the experiment for encapsulation. EVA was supplied from STR Solar company as foil with thickness of $0.40 \mathrm{~mm}$. EVA foils were dissolved in P-Xylene in different ratios of $6,10,14$ and $18 \mathrm{wt} \%$. The ratio of $18 \mathrm{wt} \%$ has resulted in homogenous layer of EVA applied on top of the cell as well as presenting good optical properties of reflection and transmission. Thus, this ratio was chosen for mixing with the luminesce phosphor.

\section{MEASUREMENT}

The electrical characteristics of the solar cells were tested on the coated and uncoated part of each cell at $25^{\circ} \mathrm{C}$ with visible light at intensity of $1000 \mathrm{~W} / \mathrm{m}^{2}$ with cell area of $8.5 \mathrm{~cm}^{2}$. Differential Scanning Calorimetry (DSC) measurements were carried out using PerkinElmer single-furnace DSC 6000 equipped with cooling accessory Intracooler 2P mechanical refrigerator. Nitrogen is used as the sample purge gas at $20 \mathrm{ml} / \mathrm{min}$. For DSC measurements, small EVA disks of about $10 \mathrm{mg}$ were cut and encapsulated in a standard aluminum pan. Photoluminescence (PL) and PL excitation (PLE) spectra were obtained using Bentham M300 monochromator with Xenon lamp as light source. Reflectance spectra were measured at room temperature using Perkin-Elmer Lambda 650S UV-Vis spectrophotometer in a spectral range from 200 to $800 \mathrm{~nm}$. The film morphology is analyzed using a ZEISS SUPRA 35VP field emission scanning electron microscope (SEM). Energy dispersive X-ray analysis (EDX) was used to confirm the presence of the coating. IQE measurements were carried out using SPEQUEST system by LOT-QuantumDesign.

\section{RESULTS AND DISCUSSION}

DSC measurement was used to find the required temperature and time for curing the EVA sheet. Figure 2 shows DSC measurements of the raw EVA material.

The first heating curve shows an endothermic melting peak of $29.67 \mathrm{~J} / \mathrm{g}$ followed by the exothermic curing peak with the curing enthalpy of $6 \mathrm{~J} / \mathrm{g}$. The second heating curve shows a smaller melting peak of $9.54 \mathrm{~J} / \mathrm{g}$ vs. $29.67 \mathrm{~J} / \mathrm{g}$ (for the first scan) and there is no detectable curing exothermal peak. So, by comparing the first heating curve with the second heating curve, it is clear that the EVA raw material is cured completely after first heating to $220{ }^{\circ} \mathrm{C}$. The influence of EVA coating on the electrical characteristics of the solar cell before and after heating is shown in Figure 3.

The EVA coated cell shows lower electrical output before heating. However, electrical output is increased after heat treatment because of increased transparency of EVA coating.

$\mathrm{Gd}_{2} \mathrm{O}_{2} \mathrm{~S}\left(\mathrm{Er}_{0.2}, \mathrm{~Tb}\right)_{0.01}$ phosphor can be excited with $292 \mathrm{~nm}$ UV light and produces green emission peaking at $545 \mathrm{~nm}$.

Figure 4 shows the PLE absorption spectrum of $\mathrm{Gd}_{2} \mathrm{O}_{2} \mathrm{~S}\left(\mathrm{Er}_{0.2}, \mathrm{~Tb}\right)_{0.01}$ phosphor in the wavelength domain of 250 to $334 \mathrm{~nm}$ and a maximal emission in the wavelength in the domain of 535 to $560 \mathrm{~nm}$. 
Since the silicon solar cell shows poor absorption in the UV spectral range, applying $\mathrm{Gd}_{2} \mathrm{O}_{2} \mathrm{~S}\left(\mathrm{Er}_{0.2}, \mathrm{~Tb}\right)_{0.01}$ phosphor on top of solar cell surface would be expected to enhance the spectral response of the cell and thus the conversion efficiency.

Figure 5 shows and compares the reflectance spectra of the uncoated, EVA coated and EVA+phosphor coated solar cells. Comparison between these cells indicates that phosphor coating on the surface of the $\mathrm{Si}$ wafer can effectively reduce reflection and increase light absorption in the entire range from 200 to $800 \mathrm{~nm}$. The coated cells show a significant reduction in the reflectance in the UV range.

Figure 6 shows the current versus voltage $(\mathrm{I}-\mathrm{V})$ curves and the power versus voltage $(\mathrm{P}-\mathrm{V})$ curves for the solar cell before and after coating at the maximum enhanced conversion efficiency obtained. It can be seen that the $\mathrm{I}_{\mathrm{SC}}$ has been increased from 280 to $289 \mathrm{~mA}$ due to spectral light conversion without any change in the open circuit voltage value. The enhancement in $\mathrm{I}_{\mathrm{SC}}$ resulted in increasing the conversion efficiency from $12.11 \%$ to $12.65 \%$.

Detailed I-V characteristics of the coated solar cells are summarized in Table 1. It can be seen that the coating contributed in enhancing the efficiency of the cells. By comparing the performances of the uncoated, EVA and phosphor coating with different percentages, the enhancement brought by EVA through reducing antireflection loss could be obtained.

Table 1. Electrical characteristics of the uncoated and coated cells at $1000 \mathrm{~W} / \mathrm{m}^{2}$ and $25{ }^{\circ} \mathrm{C}$

\begin{tabular}{c|ccccc}
\hline Cell type & $\begin{array}{c}I_{s c} \\
(\mathrm{~mA})\end{array}$ & $\begin{array}{c}V_{o c} \\
(\mathrm{mV})\end{array}$ & $\begin{array}{c}P_{\max } \\
(\mathrm{mW})\end{array}$ & $F F$ & $\begin{array}{c}\eta \\
(\%)\end{array}$ \\
\hline Uncoated & 0.280 & 0.548 & 0.0973 & 0.63 & 12.11 \\
EVA & 0.284 & 0.549 & 0.0992 & 0.64 & 12.34 \\
$1 \mathrm{mg}$ phosphor + EVA & 0.286 & 0.549 & 0.1006 & 0.64 & 12.52 \\
3 mg Phosphor + EVA & 0.289 & 0.549 & 0.1017 & 0.64 & 12.65 \\
$5 \mathrm{mg}$ Phosphor + EVA & 0.286 & 0.549 & 0.0996 & 0.64 & 12.39 \\
$7 \mathrm{mg}$ Phosphor + EVA & 0.281 & 0.548 & 0.0988 & 0.64 & 12.29 \\
\hline
\end{tabular}

Also, the results show that enhancement brought by phosphor coating with different percentages in a polymeric matrix can be also achieved. These enhancements are shown in Figure 7 in which the efficiency enhancement brought by EVA, $1 \mathrm{mg}, 3 \mathrm{mg}, 5 \mathrm{mg}, 7 \mathrm{mg}$ is $0.23 \%, 0.41 \%, 0.54 \%, 0.28 \%$ and $0.18 \%$ respectively.

As mentioned before the enhancement achieved by luminescent layer consists of two parts. One part is enhancement brought by antireflection effects of the EVA layer and the other part is the enhancement brought by the photoluminescent effects of the phosphor powder. Therefore by comparing enhancement brought by EVA and EVA with phosphor coating, the enhancement brought by down conversion effect of the luminescent layers can be obtained. For phosphor coating with $3 \mathrm{mg}$, this absolute efficiency enhancement is $+0.54 \%$ which correspond to $4.45 \%$ relative efficiency increase.

To further verify the experimental results, transmission analysis of the coated layers was investigated by coating a quartz substrate using the same condition used in coating the solar cells. It can be seen that the EVA coating has the highest transmittance. Figure 8 shows the transmission of the EVA and EVA with different phosphor concentration layers.

Transmission spectra show decrees in the transmission with increased concentration of the phosphor powder. The later explains the reduction in the $\mathrm{I}_{\mathrm{SC}}$ and thus lower conversion efficiency. Figure 9 
shows a cross section SEM image of the solar cell coated using blade screen printing technique. The image shows a good uniformity of the deposited luminescent layer with a thickness of $9.3 \mu \mathrm{m}$ on top of a pyramidally textured surface of the silicon solar cell.

The internal quantum efficiency of the uncoated cell, EVA coated and EVA doped with different concentrations of the phosphor were measured and shown in Figure 10 in order to obtain the optimum concentration of the phosphor in EVA layer. By comparing the spectra of the EVA coated cell and the phosphor incorporated into the EVA with different concentrations, an enhancement of the conversion efficiency can be detected in the spectral region corresponding to the absorption of the phosphor material incorporated in the EVA film. The increase of the concentration of the phosphor corresponds to the increase in the magnitude of IQE spectra in the UV region.

From IQE spectra, it can be seen that 1 and $3 \mathrm{mg}$ concentrations provide with a good response in the visible region. However, it can be concluded that $3 \mathrm{mg}$ is the best concentration where it shows to absorb more photons in the UV region. These results also confirm the improvement in the solar cell performance by the conversion from the short wavelengths where the reduction in reflection was found to correspond with an increase in the short circuit current of the solar cells. However, by comparing 5 and $7 \mathrm{mg}$ concentration of the phosphor and EVA coated solar cells with the uncoated solar cell, it can be seen an insignificant decrease in the visible light response of the solar cell.

This decrease in visible light response could be expected to be greater with that a higher concentration of the phosphor in the powder because the phosphor aggregate at high concentration leads poor film quality due to low transparency because of light scattering.

Figure 11 shows a low magnification SEM image of the top surface of the photoluminescent layer with $3 \mathrm{mg}$ of the phosphor. The top image of coating layer exhibits a granular feature due to phosphor particles. The presence and composition of the phosphor nanopowder were confirmed by EDX results.

\section{CONCLUSION}

We have demonstrated the possibility of enhancing the performance of commercial PV cell by using spectral conversion by applying a phosphor material dispersed in a polymeric matrix on top of monocrystalline solar cells.

Blade screen printing technique formed a good layer and this technique can be applicable to other powder phosphors. The results demonstrated that the coating can effectively increases the values of the short circuit current and consequently the conversion efficiency. An absolute enhancement of $0.54 \%$ has been demonstrated in this study. The photoluminescent layer did not serve only as a spectral conversion layer for one part of the solar spectrum but also as a low reflective layer for a different part of the solar spectrum. Thus, it can be concluded that the enhancement in the conversion efficiency is due to the effects of the properties of EVA binder and the phosphor and the top surface structure of the silicon solar cell.

In this study a wide range of characterisation tools were utilised to clearly understand the separate and combined effects of the binder and the phosphor on the solar cells performance, and the results suggest that the role of the binder is as important as the phosphor. It is essential for the binder to provide a transparent matrix for phosphor coating through optimizing the binder's curing time and temperature.

The same method can be optimized and extended to a spectral range more suitable for PV application by tuning the absorption and emission of the phosphor into more desirable wavelengths. 


\section{Acknowledgments}

Authors would like to thank $\mathrm{Mr}$ Ben Parker of LOT-QuantumDesign for facilitating QEmeasurements.

\section{REFERENCES}

1. Dimova-Malinovska D. The state-of-the-art and future development of the photovoltaic technologies the route from crystalline to nanostructured and new emerging materials. Journal of Physics: Conference Series 2010; 253: 012007.

2. Shockley W, Queisser HJ. Detailed balance limit of efficiency of $p-n$ junction solar cells. Journal of Applied Physics 1961; 32: 510-519.

3. Guo K. Green nanotechnology of trends in future energy: a review. International Journal of Energy Research. 2012; 36:1-17.

4. Trupke T, Green MA, Würfel P. Improving solar cell efficiencies by down-conversion of high-energy photons. Journal of Applied Physics 2002; 92: 1668-1674.

5. Abrams ZR, Niv A, Zhang X. Solar energy enhancement using down-converting particles: A rigorous approach. Journal of Applied Physics 2011; 109: 114905.

6. Chung P, Chung H, Holloway PH. Phosphor coatings to enhance si photovoltaic cell performance. Journal of Vacuum Science \& Technology A: Vacuum, Surfaces, and Films 2007; 25: 61-66.

7. Liu J, Wang K, Zheng W, Huang W, Li C, You X. Improving spectral response of monocrystalline silicon photovoltaic modules using high efficient luminescent down-shifting $\mathrm{Eu}^{3+}$ complexes. Progress in Photovoltaics 2013; 21: 668-675.

8. Chen J-Y, Huang CK, Hung WB, Sun KW, Chen TM. Efficiency improvement of si solar cells using metalenhanced nanophosphor fluorescence. Journal of Solar Energy Materials \& Solar Cells 2014; 120: 168174.

9. Wang $T, Y u B, H u Z$, Wang $X$, Zou G, Zhang Q. Enhancing the performance of multi-crystalline silicon photovoltaic module by encapsulating high efficient $\mathrm{Eu}^{3+}$ complex into its pre-existing EVA layer. Journal of Optical Materials 2013; 35: 1118-1123.

10. Yen-Chi C, Woan-Yu H, Teng-Ming C. Enhancing the performance of photovoltaic cells by using downconverting KCaGd(PO4)2:Eu ${ }^{3+}$ phosphors. Journal of Rare Earths 2011; 29: 907-910.

11. Marchionna S, Meinardi F, Acciarri A, Binetti S, Papagni A, Pizzini S, Malatesta V, Tubino R. Photovoltaic quantum efficiency enhancement by light harvesting of organo-lanthanide complexes. Journal of Luminescence 2006; 118: 325-329.

12. Yan $X$, Fern $G R$, Withnall $R$, Silver J. Effects of the host lattice and doping concentration on the colour of $\mathrm{Tb}^{3+}$ cation emission in $\mathrm{Y}_{2} \mathrm{O}_{2} \mathrm{~S}: \mathrm{Tb}^{3+}$ and $\mathrm{Gd}_{2} \mathrm{O}_{2} \mathrm{~S}: \mathrm{Tb}^{3+}$ nanometer sized phosphor particles. Nanoscale 2013; 5: 8640-8646.

13. CAMPBELL P, GREEN M. Light trapping properties of pyramidally textured surfaces. Journal of Applied Physics 1987; 62: 243-249.

14. Gupta R, Kumar R, Sharma A, Verma N. Novel Cu-carbon nanofiber composites for the counter electrodes of dye-sensitized solar cells. International Journal of Energy Research. 2015; 39: 668-680. 


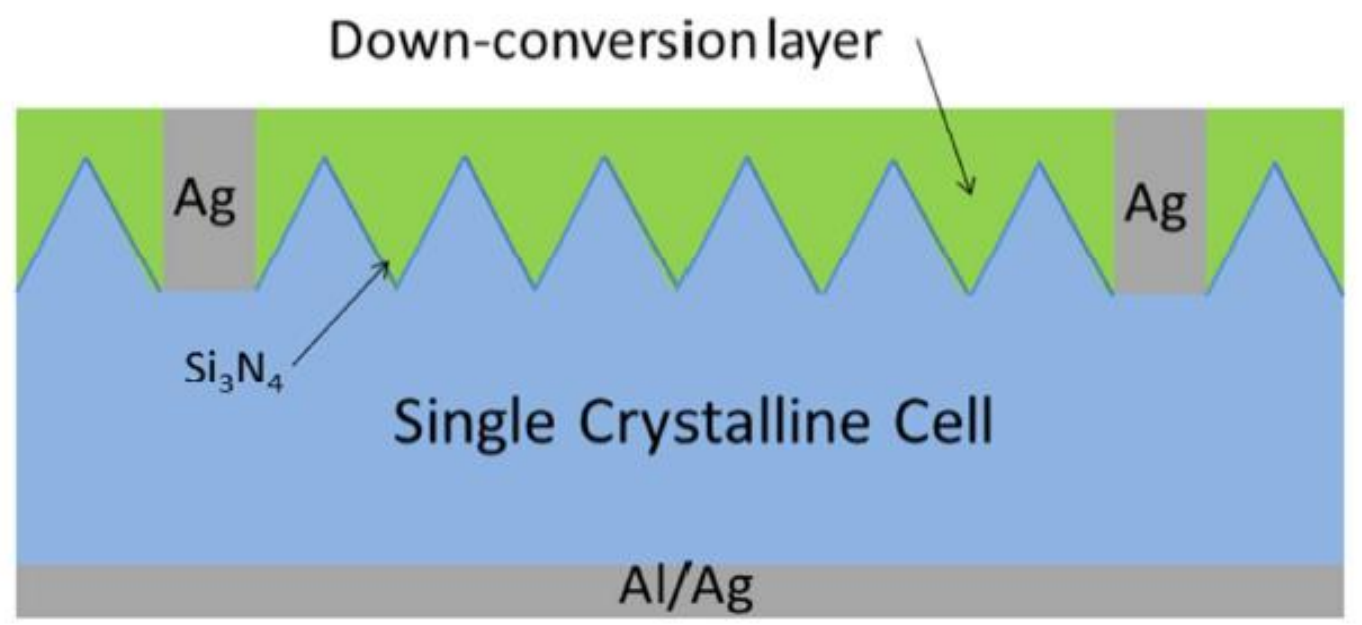

Figure 1. A schematic of the textured mono-crystalline solar cell with DC layer. $187 \times 89 \mathrm{~mm}(96 \times 96 \mathrm{DPI})$ 


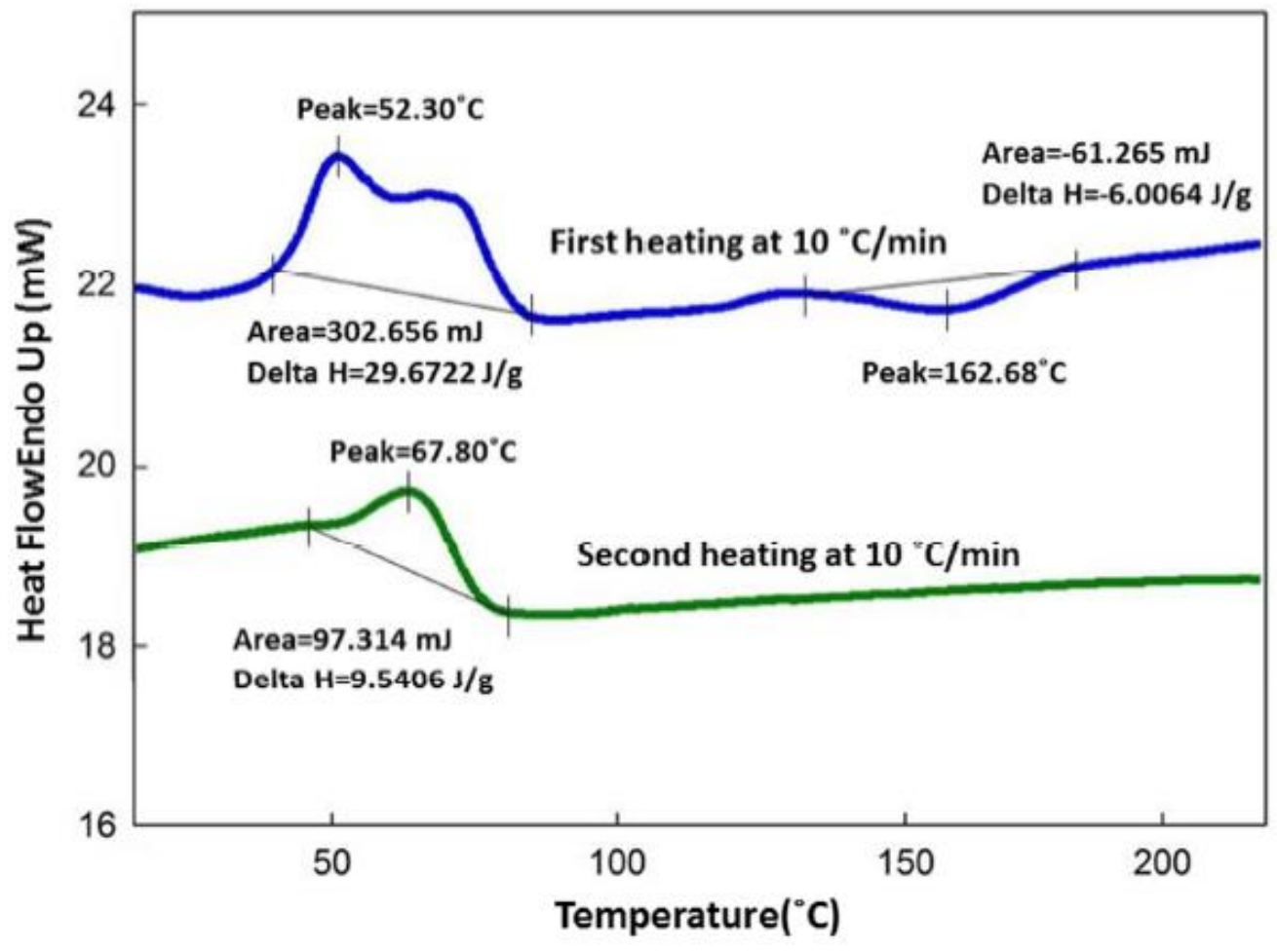

Figure 2. The first (blue) and second (green) heating curve of raw EVA material. $216 \times 161 \mathrm{~mm}(96 \times 96 \mathrm{DPI})$ 


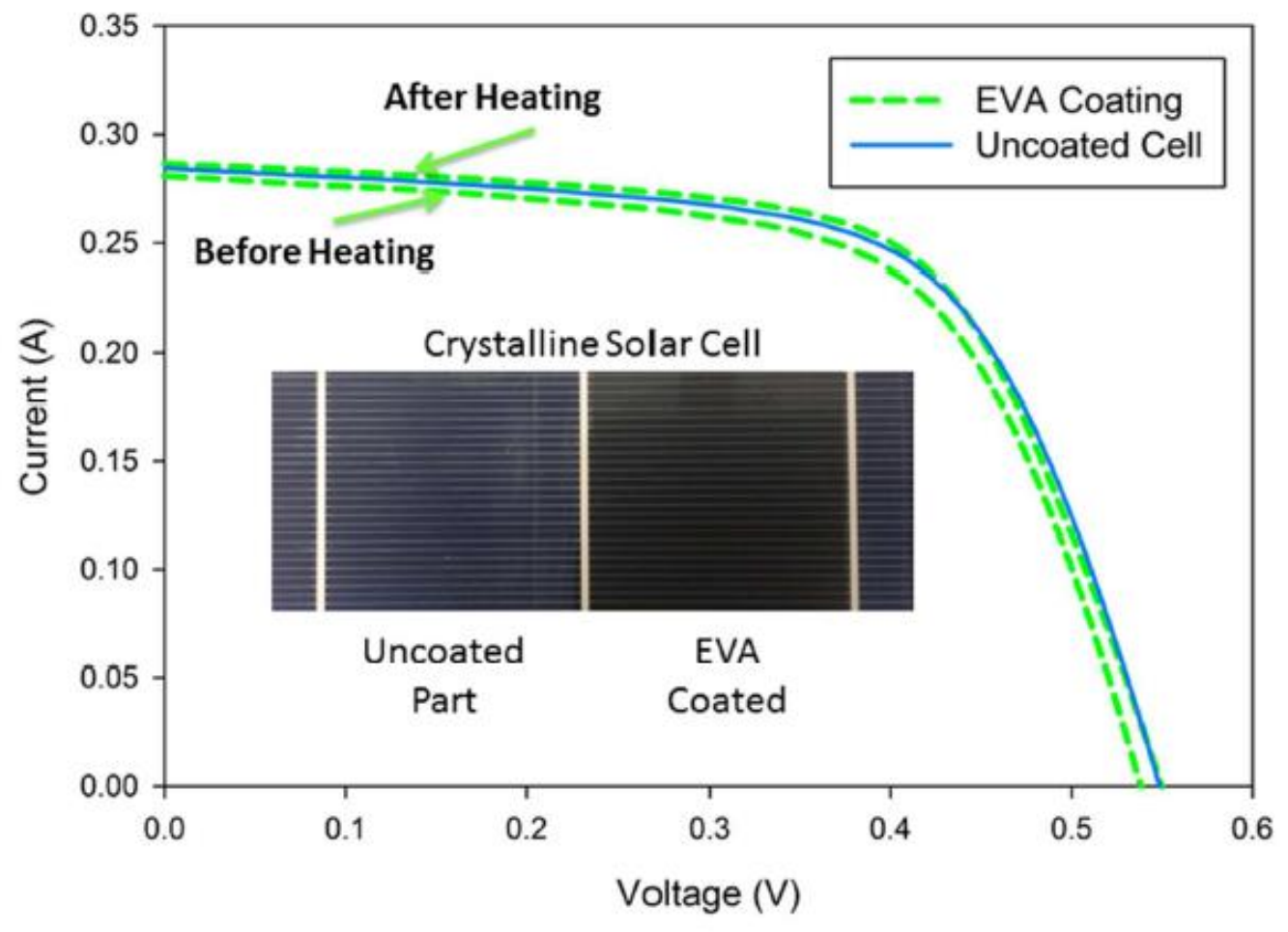

Fiqure 3. IV curve of EVA coating before and after heat treatment. $196 \times 143 \mathrm{~mm}(96 \times 96$ DPI) 


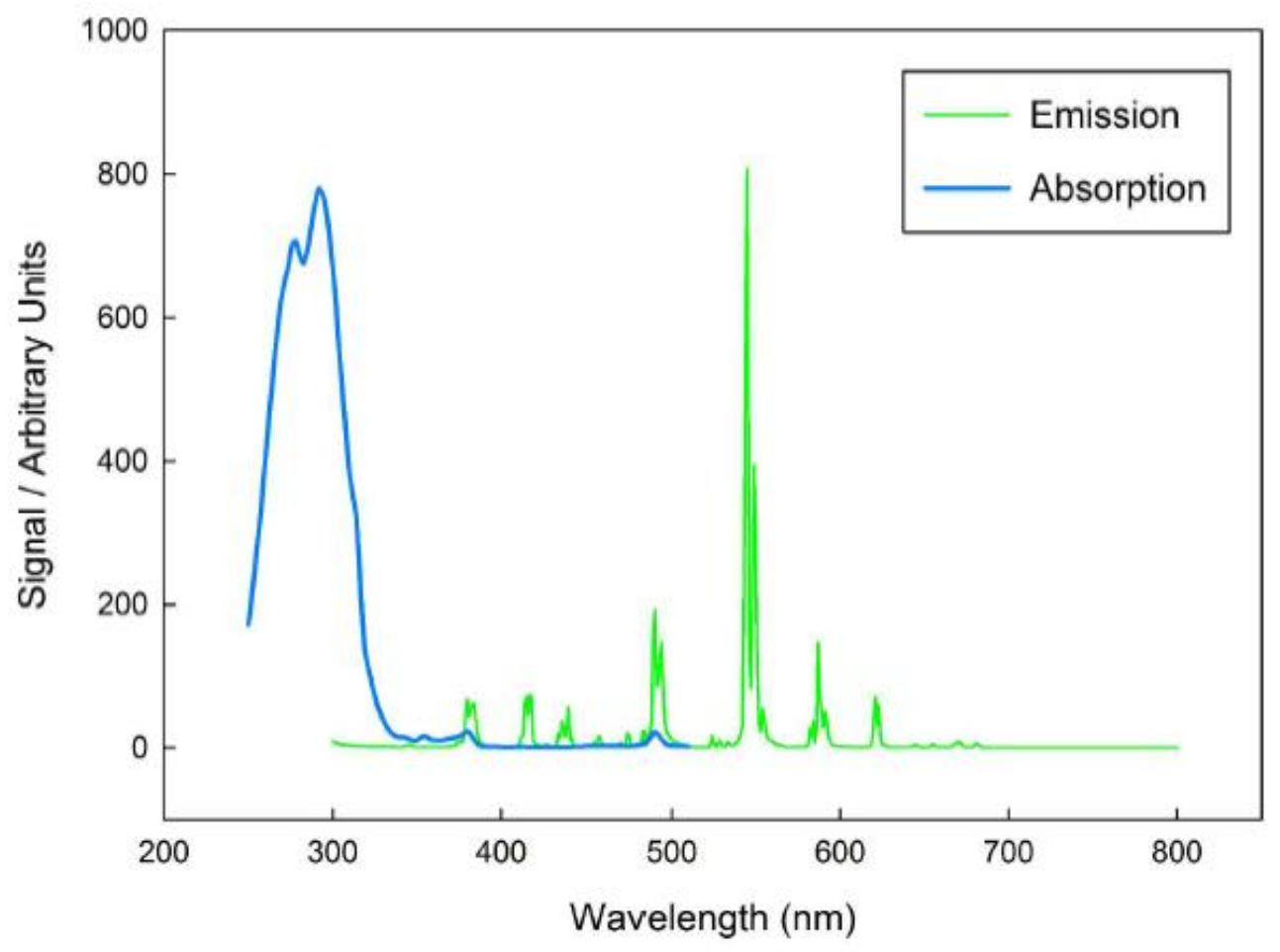

Figure 4. PLE and PL of $\mathrm{Gd}_{2} \mathrm{O}_{2} \mathrm{~S}\left(\mathrm{Er}_{0.2}, \mathrm{~Tb}\right)_{0.01}$ at room temperature. $902 \times 664 \mathrm{~mm}(96 \times 96 \mathrm{DPI})$ 


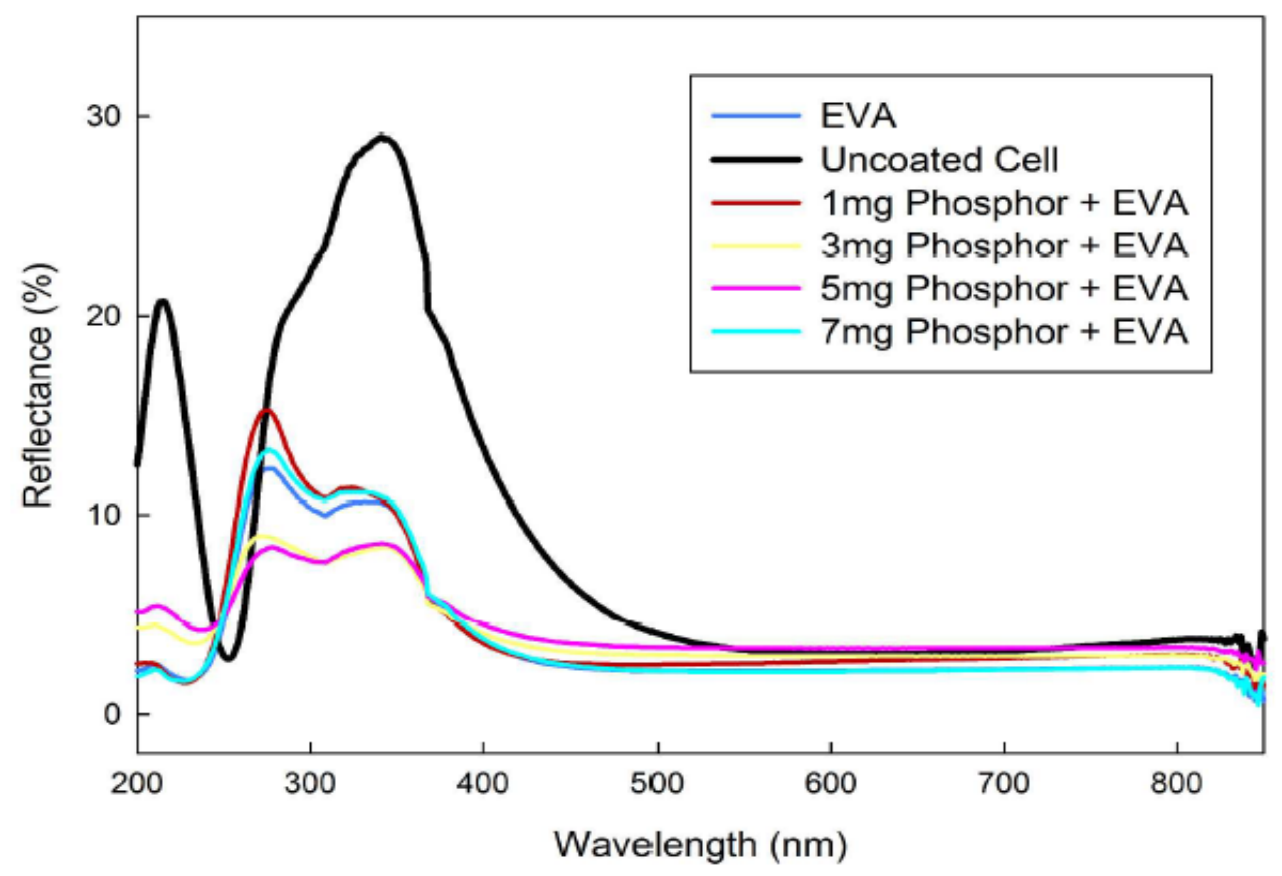

Figure 5. Comparison of reflectance spectra for uncoated and coated cells. $881 \times 654 \mathrm{~mm}(96 \times 96 \mathrm{DPI})$ 


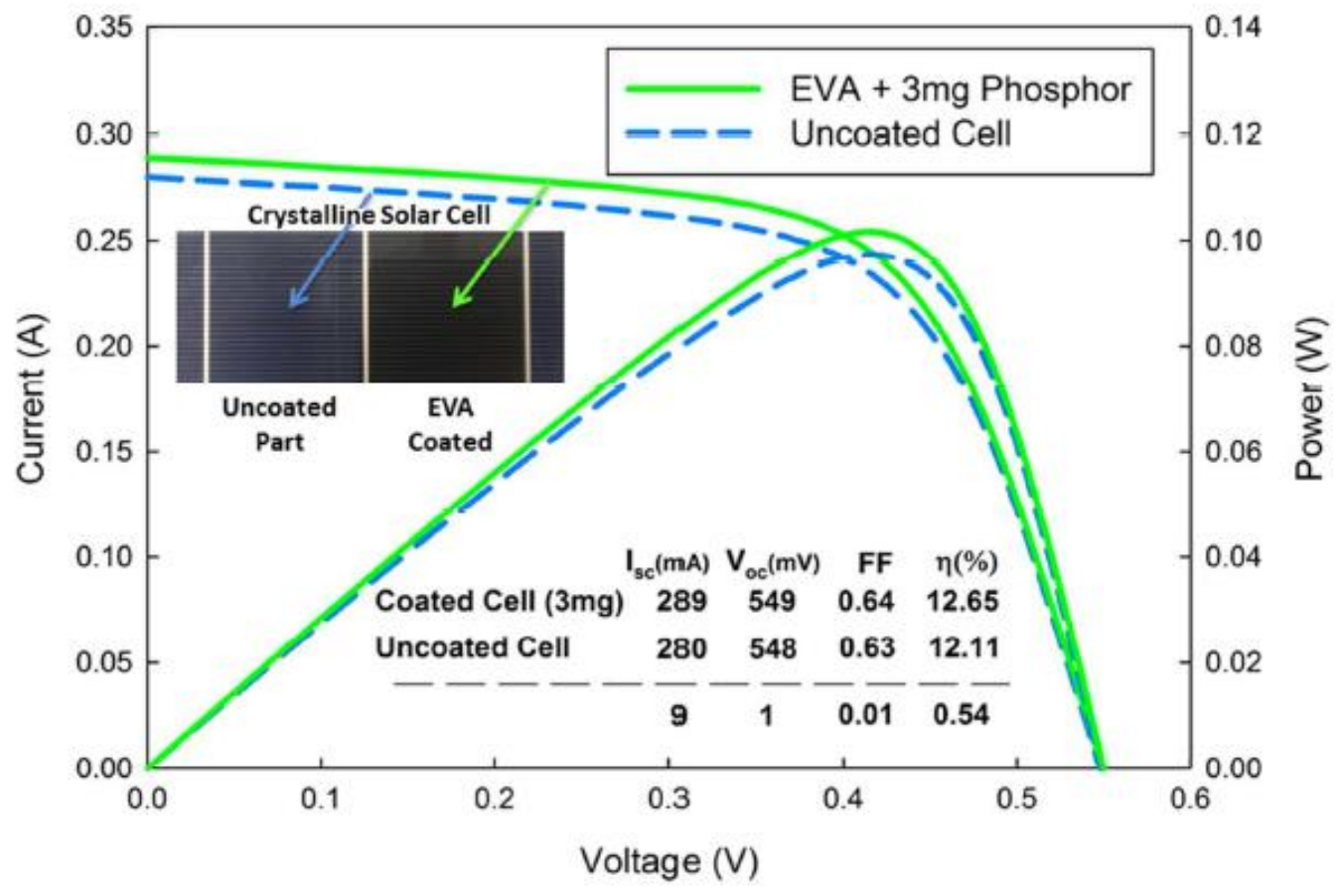

Figure 6. I-V and P-V curves of the solar cells at the maximum enhancement. $231 \times 155 \mathrm{~mm}(96 \times 96$ DPI $)$ 


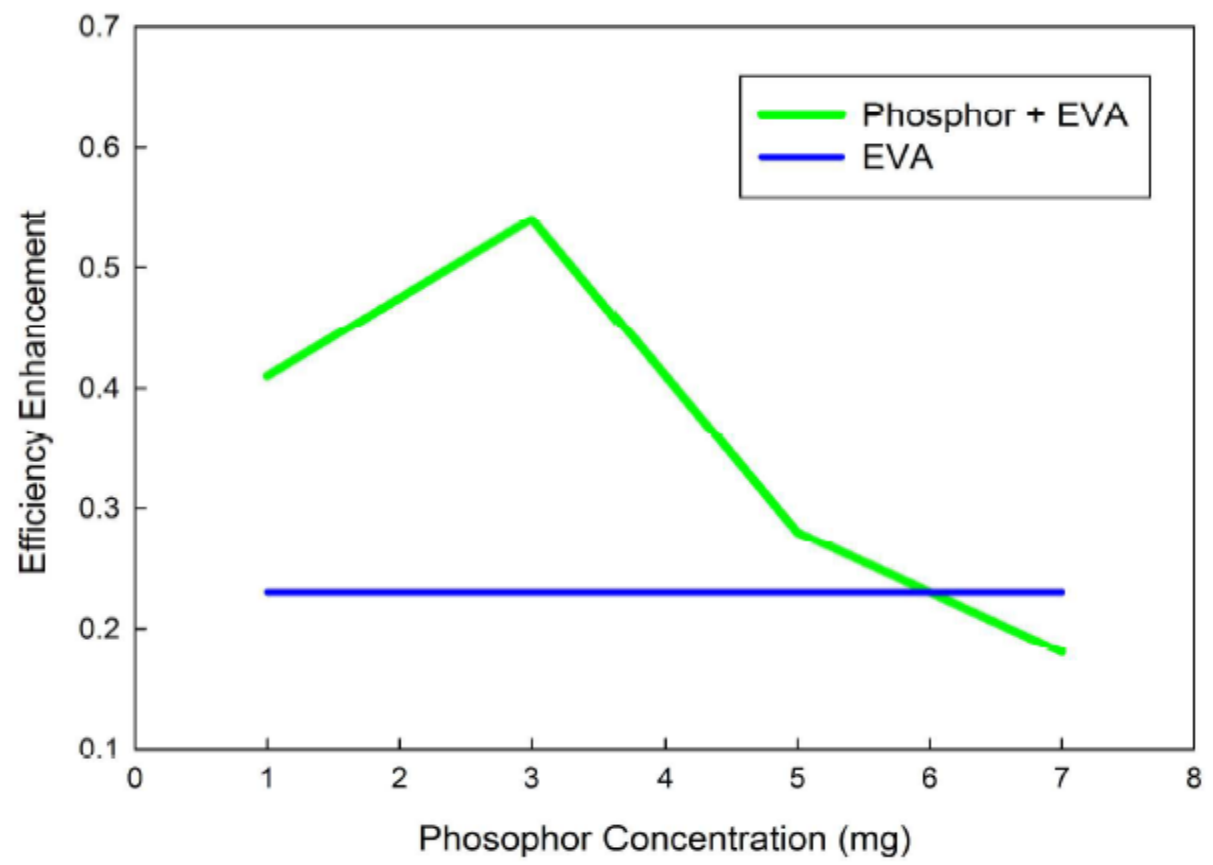

Figure 7. Efficiency enhancement of the coated solar cells. $878 \times 665 \mathrm{~mm}(96 \times 96 \mathrm{DPI})$ 


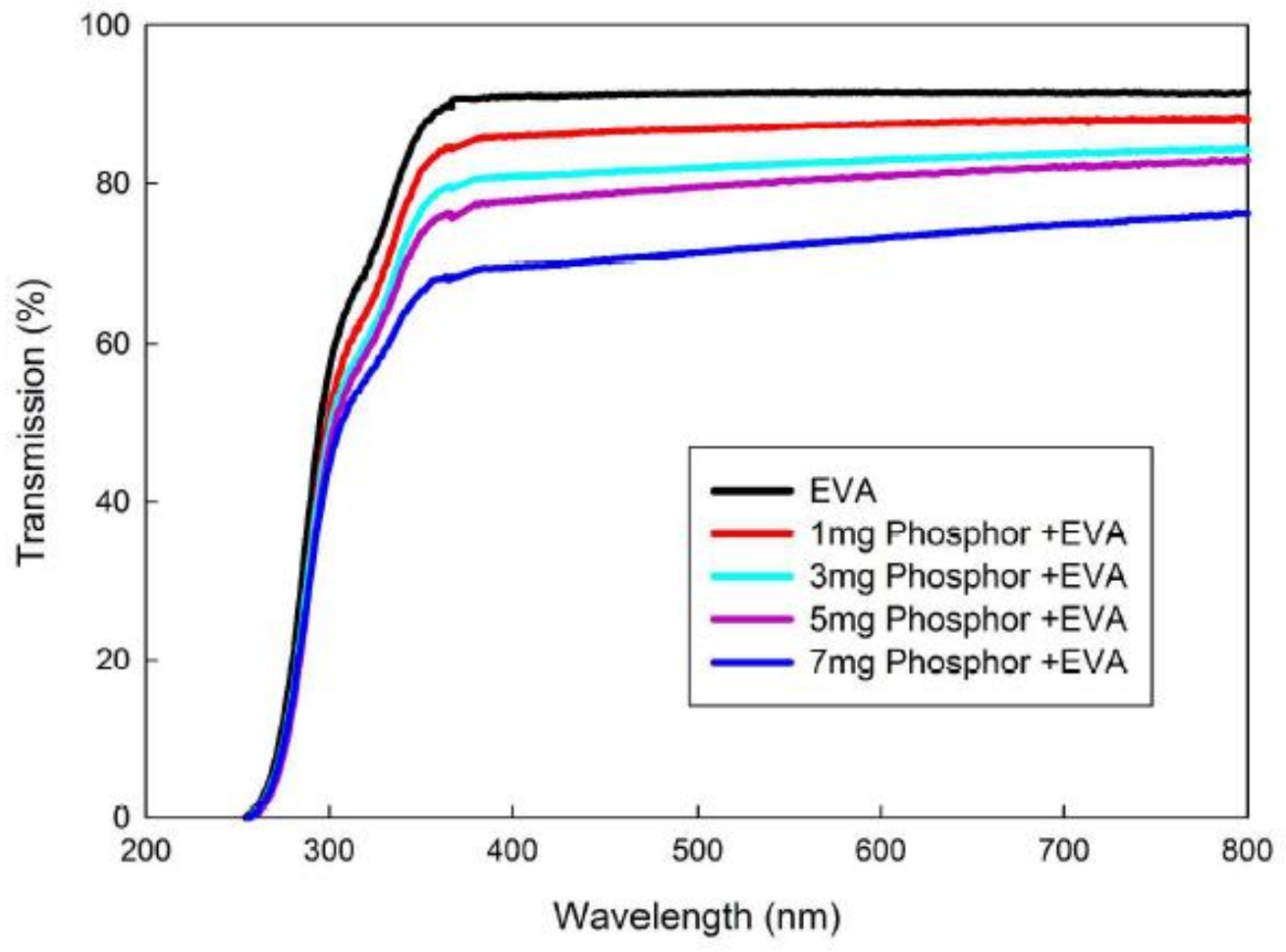

Figure 8. Transmission spectra of the coated layers. $914 \times 677 \mathrm{~mm}(96 \times 96 \mathrm{DPI})$ 


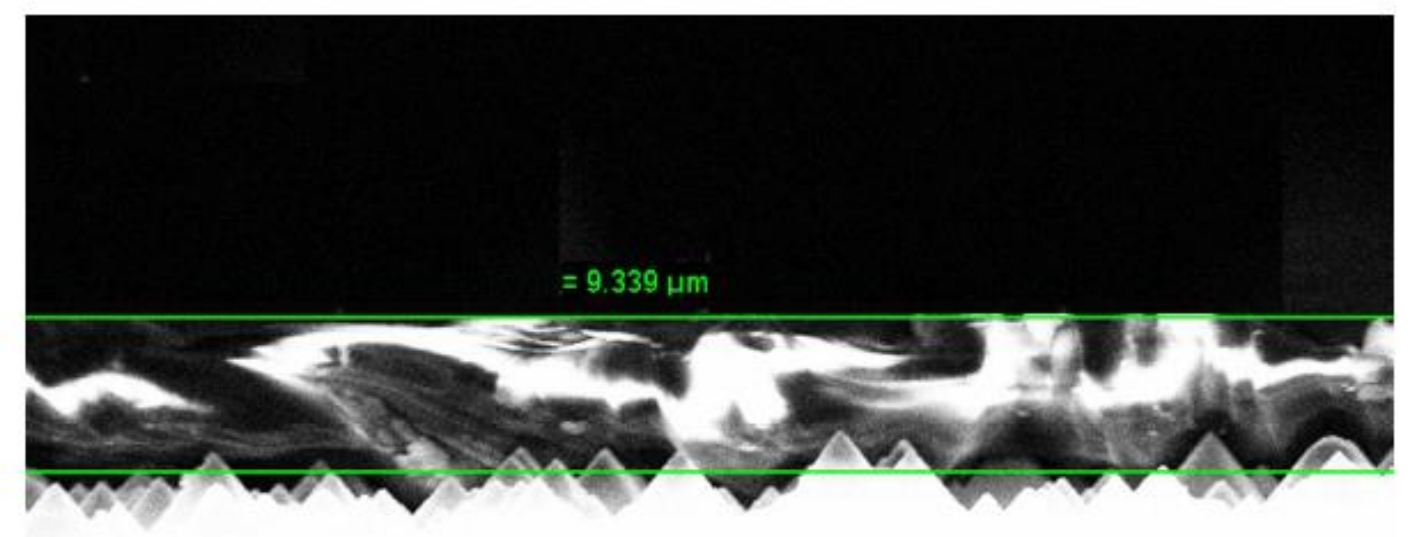

\section{0um}

Figure 9. Cross section SEM image of the coated cell with EVA+phosphor. $297 \times 148 \mathrm{~mm}(72 \times 72$ DPI $)$ 


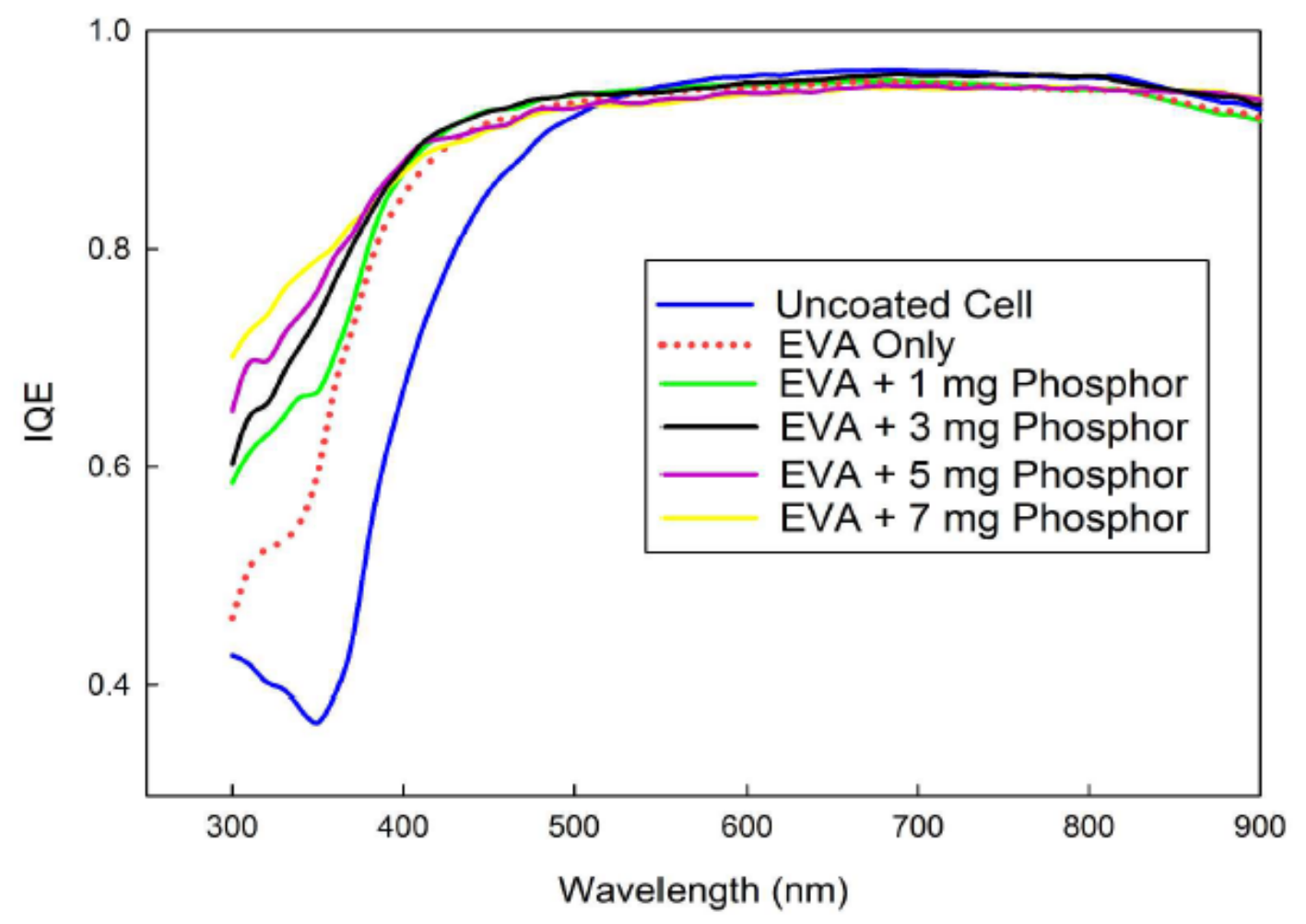

Figure 10. IQE spectra of the solar cells. $902 \times 678 \mathrm{~mm}(96 \times 96 \mathrm{DPI})$ 


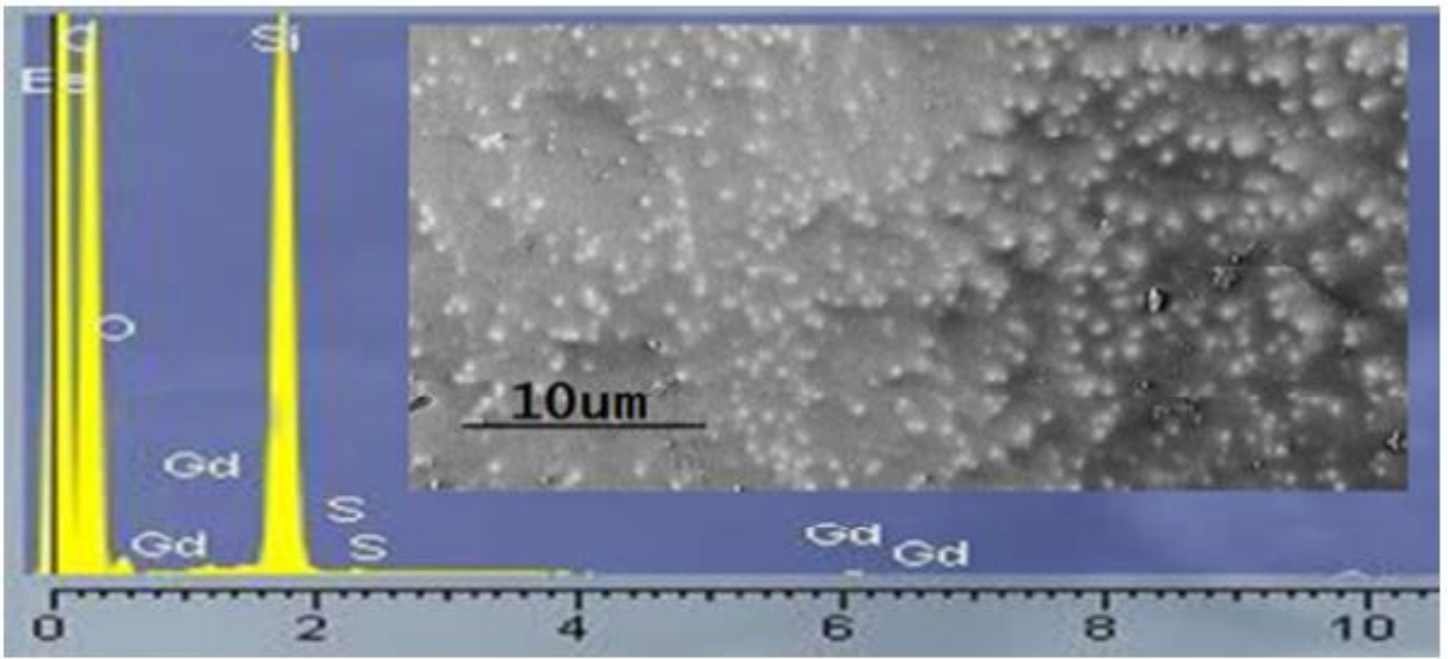

Figure 11. EDX spectrum and top SEM image of the coated solar cell. $138 \times 62 \mathrm{~mm}(96 \times 96 \mathrm{DPI})$ 